\title{
Chapter 10 \\ Delivering Perennial New and Orphan Crops for Resilient and Nutritious Farming Systems
}

\author{
Ian K. Dawson, Stepha McMullin, Roeland Kindt, Alice Muchugi, \\ Prasad Hendre, Jens-Peter B. Lillesø, and Ramni Jamnadass
}

\subsection{Introduction}

Sub-Saharan Africa (SSA) has areas of high 'hidden hunger' so improving food nutritional quality is crucial (von Grebmer et al. 2014). One method, that is supported by governments in the region (Covic and Hendricks 2016), is the diversification of food systems. In the context of climate-change-related challenges, this approach may have significant benefits compared to alternative methods such as biofortification, as diversity can promote resilience to more variable environmental conditions that negatively affect individual crops (Ray et al. 2012). Diversity-based resilience is, for example, possible through mechanisms including risk spreading and positive stabilising interactions in production (Altieri et al. 2015; for a wider discussion on diversity-stability relationships see Thibaut and Connolly 2013). One crop diversification approach recommended for the region is promoting 'new and orphan crops' (NOC) that include many perennial foods. These are novel or traditional crops that-although important to consumers and farmers-have largely been neglected by researchers and businesses (Dawson et al. 2018b). They are, however, often nutrient-rich and frequently have properties that support their integration into existing food systems, potentially countering increasing reliance on a narrow range of calorie-rich but nutritionally limited foods (Khoury et al. 2014).

Despite their apparent potential, analysis of the contributions of perennial NOC to the resilience of African food systems is limited. In this paper, we help to fill this

I. K. Dawson $(\varangle)$

World Agroforestry Centre (ICRAF), UN Avenue, Nairobi, Kenya

Scotland's Rural College (SRUC), Edinburgh, UK

S. McMullin $\cdot$ R. Kindt $\cdot$ A. Muchugi $\cdot$ P. Hendre $\cdot$ R. Jamnadass

World Agroforestry Centre (ICRAF), UN Avenue, Nairobi, Kenya

J.-P. B. Lilles $\varnothing$

Forest \& Landscape Denmark, University of Copenhagen, Copenhagen, Denmark 
knowledge gap through two approaches applied to eastern and southern African nations. First, we process community-level production data sets to see if perennial NOC species can help fill seasonal gaps in diets subnationally, as part of 'crop portfolios'. Second, using country-level data sets on perennial and annual crop production that are freely available through FAOSTAT (FAOSTAT 2017; see Garibaldi et al. 2011; Khoury et al. 2014 as quoted in the current paper for other examples of the use of these or derived data sets), we explore year-on-year variability in yields for a subset of nations in the region. Beyond this, we explore constraints to perennial NOC integration into the region's food systems, again making use of FAOSTAT data; we also outline some current approaches to overcoming these barriers. We reference the work of the African Orphan Crops Consortium (AOCC 2018) which focuses on production-based NOC interventions, including the training of African plant breeders to use advanced crop improvement methods. Although crop improvement is essential, we outline coinvestments that are also necessary, including in delivery systems to supply improved and adapted planting material of perennial NOC to farmers.

\subsection{Can Perennial NOC Contribute to the Resilience of Eastern and Southern African Food Systems?}

\subsubsection{Perennial NOC Foods and Crop Portfolios}

To explore if perennial NOC foods can support seasonal gaps in diets that may be vulnerable to climate-change-related alterations in weather patterns, we have surveyed food systems in rural locations in a range of African countries. The methods for this research have been described elsewhere (McMullin et al. 2017), but involve characterising socio-ecological site-specific food production and consumption information, including the seasonal availability of foods. Food insecurity among farming households is also estimated.

This research shows that perennial NOC foods can be highly important for supporting local consumers' diets in food insecure months at a subnational level in African countries, as illustrated by the case of Siaya County in southwestern Kenya (Fig. 10.1). In addition to filling harvest gaps, the portfolio is adjusted to address certain nutrient gaps, such as in pro-vitamins $\mathrm{A}$ and $\mathrm{C}$ that are often lacking in diets in SSA and whose absence has significant detrimental health consequences. Selected crop portfolios are then recommended to farmers for specific locations.

This analysis is based on consumption being tightly linked with what foods are produced locally. While such a connection is often found in subsistence farming (Powell et al. 2015), incomes and market access affect the relationship (Sibhatu et al. 2015). These aspects require further exploration, while across-season measurements are required to account for the effects of changing weather patterns on crop phenologies, to better model climate change effects. 

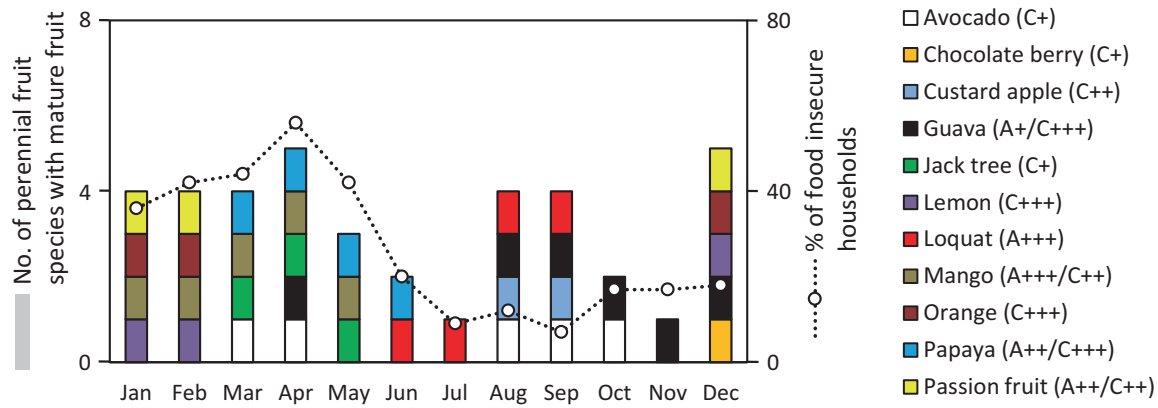

Fig. 10.1 Monthly mapping of harvest periods of prioritised perennial fruits overlaid with information on household food insecurity for Siaya County in Western Kenya. Analysis was based on a survey of 275 farm households. Pro-vitamin A and C content of different fruits is indicated (+++ = high, $++=$ medium,$+=$ low). Perennial crops that fruited in the most food insecure month (April) and that had high or medium levels of both pro-vitamins A and $\mathrm{C}$ were mango and papaya, both of which are classified as orphan crops in the SSA region (AOCC 2018). Promoting these perennial orphan species in Siaya County may be an effective means of ensuring access to vitamins A and C in food insecure periods. Source: ICRAF Fruiting Africa Project

\subsection{Perennial Foods and FAOSTAT Yield Stabilities}

To explore the usefulness of FAOSTAT data sets for assessing the ability of perennial foods to support the resilience of food systems in eastern and southern Africa, we extracted annual yield time series for the years 1961-2014 for a range of 12 annual and perennial crops (or groups of crop species) from ten countries in the region (Table 10.1). The crops chosen are representative of food production and, in the case of the chosen perennials, are either NOC (cashew, coconut and the pooled FAOSTAT crops mango, mangosteens and guava [these last crops are considered a single crop in FAOSTAT reporting] are all entries on the AOCC's crop list; AOCC 2018) or are proxies for NOC for which production data are not yet available. The non-orphan perennials chosen as proxies were coffee, date and orange. This is because, like the majority of perennial NOC considered by the AOCC (2018), the crop product is based on fruit production. These crops can support diets directly or provide incomes to buy food.

We converted yield data for these crops into fractional year-on-year yield changes and applied a logarithmic transformation for scaling purposes, based on the approaches outlined in Dawson et al. (2018a) (see also this reference for some of the caveats in the use of FAOSTAT data sets that we do not describe fully here, but that include the different levels of accuracy in reporting for different types of crop; a measure to take this into account in our analysis involved the exclusion of countrycrop combinations if there were many identical yield values given over the time series). This analysis provides a measure of yield stability over the last half-century for individual country-crop combinations that can be summed across nations to provide overall estimates of the stability of annual and perennial crop production. 
Table 10.1 Ten eastern and southern African countries for extraction of FAOSTAT (2017) production (yield and value) data for the 12 indicated crops for the time period 1961-2014. Half of the crops chosen were annual and half perennial. Perennial crops were either orphan crops (AOCC 2018) or proxies. Where country reporting boundaries have changed within the assessed time period, information was compiled within common notional boundaries. Crops with the least stable production (yield) characteristics are listed (see text for further explanation)

\begin{tabular}{|c|c|c|c|}
\hline Country & Annual (A) crops & Perennial $(\mathrm{P})$ crops & $\begin{array}{l}\text { Least stable } \\
\text { production } \\
\text { (yield) (1st, 2nd) }\end{array}$ \\
\hline $\begin{array}{l}\text { Ethiopia PDR (or } \\
\text { Ethiopia + Eritrea) }\end{array}$ & $\begin{array}{l}\text { Chick peas, maize, } \\
\text { millet, sorghum }\end{array}$ & Coffee (green) & $\begin{array}{l}\text { Sorghum, chick } \\
\text { peas }\end{array}$ \\
\hline Kenya & $\begin{array}{l}\text { Maize, millet, potatoes, } \\
\text { sorghum }\end{array}$ & $\begin{array}{l}\text { Cashew nuts (with shell), } \\
\text { coffee (green), [Mangoes }+ \\
\text { mangosteens + guavas] } \\
\text { oranges }\end{array}$ & Millet, sorghum \\
\hline Malawi & $\begin{array}{l}\text { Chick peas, groundnuts } \\
\text { (with shell), maize, } \\
\text { potatoes, sorghum }\end{array}$ & $\begin{array}{l}\text { Coffee (green), [Mangoes + } \\
\text { mangosteens + guavas }]\end{array}$ & Sorghum, maize \\
\hline Mozambique & $\begin{array}{l}\text { Groundnuts (with shell), } \\
\text { maize, potatoes, } \\
\text { sorghum }\end{array}$ & $\begin{array}{l}\text { Cashew nuts (with shell), } \\
\text { coconuts }\end{array}$ & Maize, sorghum \\
\hline Somalia & $\begin{array}{l}\text { Groundnuts (with shell), } \\
\text { maize, sorghum }\end{array}$ & Coconuts, dates, oranges & Sorghum, maize \\
\hline $\begin{array}{l}\text { Sudan (former) (or } \\
\text { Sudan + South } \\
\text { Sudan) }\end{array}$ & $\begin{array}{l}\text { Chick peas, groundnuts } \\
\text { (with shell), millet, } \\
\text { potatoes, sorghum }\end{array}$ & Dates, oranges & $\begin{array}{l}\text { Chick peas, } \\
\text { millet }\end{array}$ \\
\hline Uganda & $\begin{array}{l}\text { Chick peas, groundnuts } \\
\text { (with shell), maize, } \\
\text { millet, potatoes, } \\
\text { sorghum }\end{array}$ & Coffee (green) & $\begin{array}{l}\text { Coffee (green), } \\
\text { chick peas }\end{array}$ \\
\hline $\begin{array}{l}\text { United Republic of } \\
\text { Tanzania }\end{array}$ & $\begin{array}{l}\text { Chick peas, groundnuts } \\
\text { (with shell), maize, } \\
\text { millet, potatoes, } \\
\text { sorghum }\end{array}$ & $\begin{array}{l}\text { Cashew nuts (with shell), } \\
\text { coconuts, coffee (green), } \\
\text { [Mangoes + mangosteens + } \\
\text { guavas] }\end{array}$ & $\begin{array}{l}\text { Cashew nuts } \\
\text { (with shell), } \\
\text { maize }\end{array}$ \\
\hline Zambia & $\begin{array}{l}\text { Groundnuts (with shell), } \\
\text { maize, millet, potatoes, } \\
\text { sorghum }\end{array}$ & Oranges & Maize, sorghum \\
\hline Zimbabwe & $\begin{array}{l}\text { Groundnuts (with shell), } \\
\text { maize, millet, potatoes, } \\
\text { sorghum }\end{array}$ & Oranges & Maize, millet \\
\hline
\end{tabular}

${ }^{\mathrm{a}}[]$ Considered as a single crop in FAOSTAT

In theory, perennial species could offer greater yield stability than annuals over time series because crop establishment—which is based on an individual season's weather at the time of planting - is a 'one-off' event for perennials, after which production can continue over a number of years. This is unlike the situation for annual crops for which production depends on the right conditions for establishment in each new season (e.g. the right amount of rainfall, without drought or flood). Conversely, many perennial crops have some degree of dependence on animal 
pollinators, while a large number of staples rely on wind- or self-pollination. For this reason, perennials' yields may be more susceptible to the vagaries of weather that influence the behaviour of animal pollinators (Garibaldi et al. 2011).

Our analysis (Fig. 10.2a) indicates that for individual countries in eastern and southern Africa the tested crops with the least stable yields vary, depending on the country. Of the 68 country-crop combinations that we analysed, however, while 21 combinations involved perennial crops $(31 \%)$ and the remainder were for annuals, only 2 of the 20 least stable country-crop combinations involved perennial species (10\%), suggesting that perennial crops overall display more stable production characteristics than annuals (see also Table 10.1). This is supported by an analysis of absolute deviations in transformed year-on-year yield changes that averages results across nations and crops, where overall deviations are lower for perennials than annuals (Fig. 10.2b). Our current analysis does not further explore the reasons for this stability; but, in some cases, it may reflect greater investments in production for what are sometimes valuable perennial commodities rather than intrinsic differences in their stability compared to annuals.

As expected, based on different production ecologies, individual country profiles of crops (Fig. 10.2a) indicate that directions in yield change for any particular yearto-year interval vary depending on the crop. This raises the prospect of actively designing compensatory crop combinations, where crops with different responses are deliberately combined to support resilience to variable seasonal conditions. To explore this issue further, we took the two countries with the highest number of crops, Kenya $(\mathrm{N}=8)$ and Tanzania $(\mathrm{N}=10)$ and, for each crop-crop combination in each nation, regressed transformed fractional year-on-year yield changes against each other. The results demonstrated that most comparisons had positive associations (40 of all comparisons, summing for both countries), indicating that yields for a pair of crops increase or decrease in the same direction over tested yearly intervals. However, in 33 cases the association was negative, indicating that yield for one member of a pair of crops increased and yield for the other decreased over yearly intervals.

The majority of positive associations indicates that most crops respond similarly to climatic conditions for a particular season; but the negative associations also indicate the possibilities for deliberate planning of compensatory crop combinations on a country-specific basis. Applying an initial probability test to regressions of paired comparisons only revealed a few to be of statistical significance $(P \leq 0.05)$ (Fig. 10.3); but, in the case of Tanzania, the one significant negative correlation observed was for an annual-perennial crop pair (potato-coffee, Fig. 10.3b). This raises the prospect that perennial crops could have a particularly important role in defining compensatory crop combinations. A more complete analysis would, however, compare a wider range of countries and crops. In addition, it would explore weather data over the time period to try and identify the causal factors behind yield changes for specific crops, to establish the mechanisms involved and possible stabilising responses on an individual crop basis.

Because of the caveats associated with the use of FAOSTAT data sets for such analyses (Dawson et al. 2018a), alternative across-species crop production data sets 


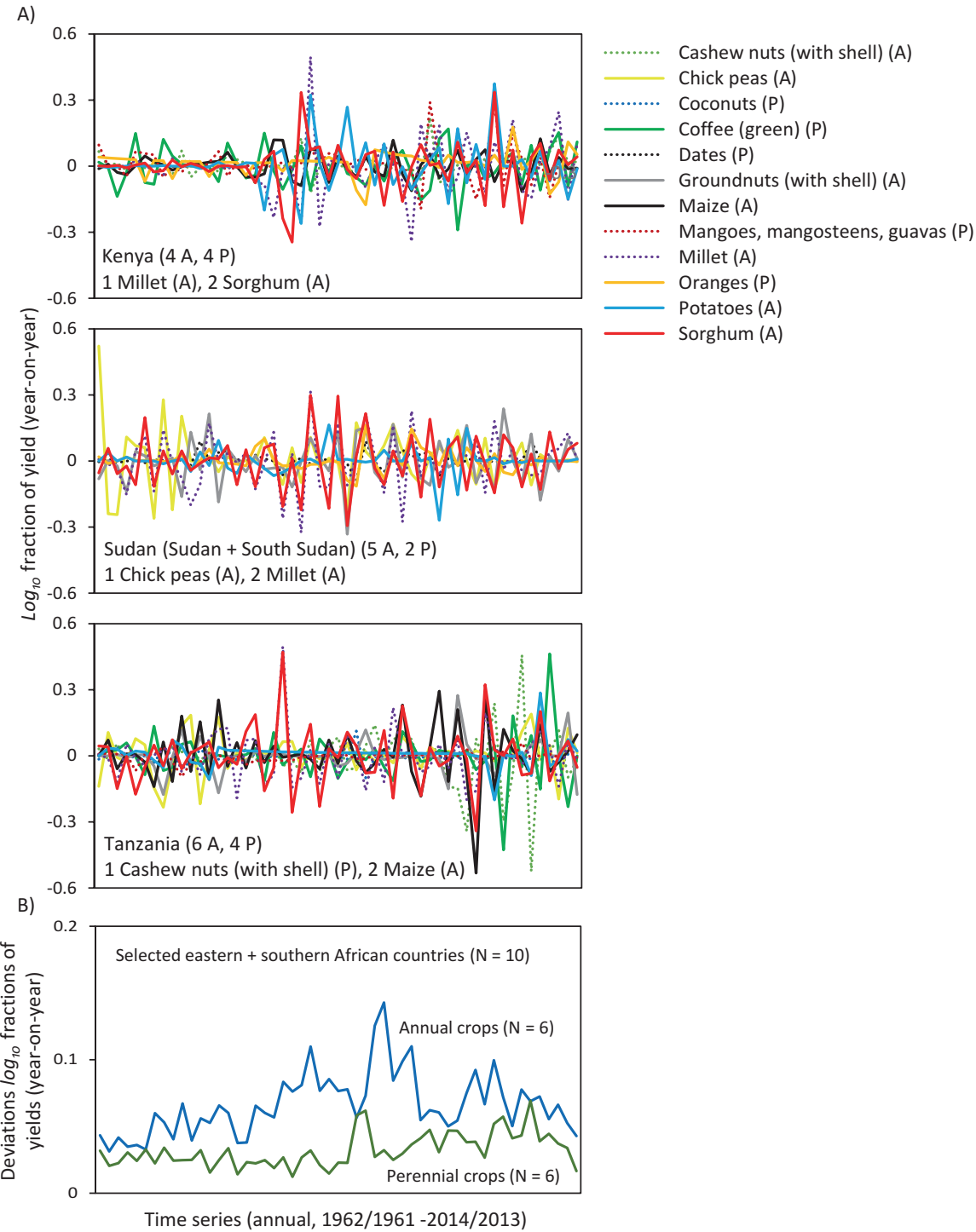

Fig. 10.2 Year-on-year yield instability for annual and perennial crops for (a) a subset of analysed countries from eastern and southern Africa and (b) averaged for each crop across nations and then across crops, based on FAOSTAT (2017) data. In (a), the $y$-axis represents a logarithmic transformation of fractional year-on-year yield changes that is an indication of the instability of production. The two crops with the least stable production characteristics for each country, as measured by the greatest amplitude in consecutive values along the $y$-axis, are given (see Table 10.1 for this information for all 10 tested countries). In (b), the same values for instability are used as in (a), but with the sign of the year-on-year change in yield removed to allow summing across countries and crops (see Table 10.1 for crops and countries included in (b) calculations) 
A) Kenya

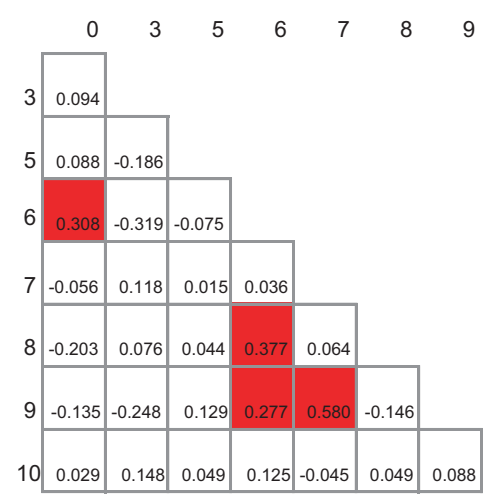

0 Cashew nuts (with shell)

1 Chickpeas

2 Coconuts

3 Coffee (green)

4 Groundnuts (with shell)

5 Maize

6 Mangoes, mangosteens, guavas

7 Millet

8 Oranges

9 Potatoes

10 Sorghum

\section{B) Tanzania}

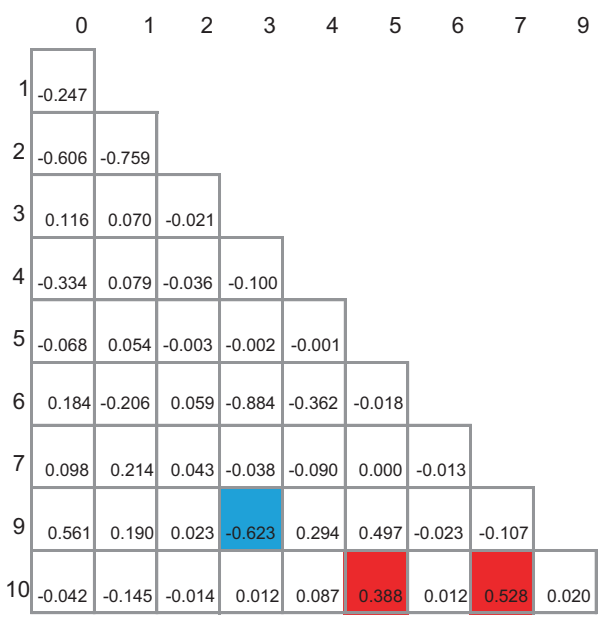

Positive correlations $(P \leq 0.05)$

Negative correlations $(P \leq 0.05)$

Fig. 10.3 Regressions of transformed fractional year-on-year yield changes (see Fig. 10.2a) for pairs of crops in (a) Kenya and (b) Tanzania, based on FAOSTAT (2017) data. Values in the matrix indicate the strength of the correlation, with matrix cells in red and blue indicating statistically significant positive and negative correlations $(P \leq 0.05)$, respectively, in initial tests (without correcting for the total number of tests)

should also be explored and, if necessary, de novo collections of crop yields made. Such data collection should ideally be on a subnational basis, since changing patterns of production can be site-specific. Our analysis of FAOSTAT data should, therefore, only be considered as an exploratory starting point. 


\subsection{What Measures Are Needed to Drive Perennial NOC Integration into Eastern and Southern African Food Systems?}

As illustrated above, analyses of the timings of food production in crop portfolios, and of FAOSTAT data sets, support the role that perennial crops, including perennial NOC, can play in supporting resilient, nutritious food systems in eastern and southern Africa at subnational and country levels. This is provided proper consideration is also given to crop features such as reproductive mechanisms and nutritional compositions. In common with production systems globally, however, there is an increasing reliance on less diverse and less nutritious foods in the region, with most research efforts focused on a few major annual crops (Khoury et al. 2014). This is demonstrated by trends in gross production value for annual and perennial crops in eastern and southern Africa, which show greater relative value accruing to annuals over the last half-century (Fig. 10.4a, based on the same sets of crops analysed in Table 10.1 and Fig. 10.2b). On the other hand, while increases in yields of annual crops have, relatively speaking, fallen behind in eastern and southern Africa, compared to the world as a whole (Fig. 10.4b), this is not as evident for perennial crops (where yield increases generally have been lower, Fig. 10.4c), which could suggest that in the latter case there are opportunities for the region to take a lead in engaging with consumer markets if production improvements can be introduced there.

As already noted, however, production research on NOC has generally been neglected (Dawson et al. 2018b). To support production improvements in SSA, therefore, the AOCC (AOCC 2018) was set up to develop advanced breeding methods and related resources. The 101 NOC considered by AOCC were prioritised to be of nutritional importance to local consumers in the region, and half of them are perennial species. The advanced methods being developed are based on next generation breeding technologies that include genomic selection and marker-trait associations to expe-

A)

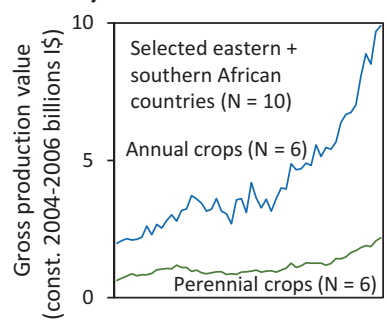

B)

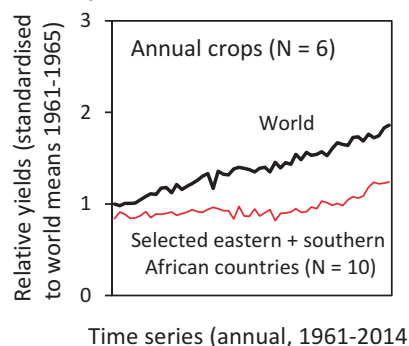

Time series (annual, 1961-2014)
C)

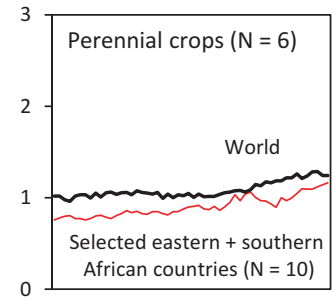

Fig. 10.4 Trends in (a) gross production value and (b, c) yields in annual and perennial crops. In (a), values are given in summed billions of constant international US Dollars for the annual and perennial crops and eastern and southern Africa countries listed in Table 10.1. In (b, c), yields from the same crops and African countries are standardised to world means for these crops for the period 1961-1965 (Source: FAOSTAT 2017) 
dite the breeding cycle (Hickey et al. 2017). The 101 chosen NOC typically have not passed through intensive domestication to improve traits related to yield, quality and labour intensity, that are particularly important to SSA producers and consumers. This is especially so for the perennial species on the AOCC list, many of which are essentially indigenous wild species. This means that there are large pools of genetic variation that can be exploited in improvement programmes that could, in addition to the above traits, also specifically consider environmental adaptation to conditions such as elevated temperatures, increased carbon dioxide levels, increased salinity, drought and flooding that are associated with climate change (Dawson et al. 2011).

A key part of the AOCC initiative is building capacity to improve NOC via the training of African plant breeders in modern genetic improvement approaches. To date, more than 80 breeders have been trained through the AOCC's UC Davis African Plant Breeding Academy, with more than half coming from eastern and southern Africa (in particular, Ethiopia, with 13 trained breeders). Related initiatives that train plant breeders also exist elsewhere in SSA (e.g. the West African Centre for Crop Improvement; WACCI 2018) which, together with the Academy, provide a significant increase in the region's capacity to drive production improvements in African crops that include NOC_-although most of the breeders currently work on annual rather than perennial crops. This training needs to be combined with funded crop improvement programmes that include field trial evaluation. In the case of perennial NOC improvement programmes in eastern and southern Africa, current field trials include those of ICRAF and partners on a range of species (Fig. 10.5).

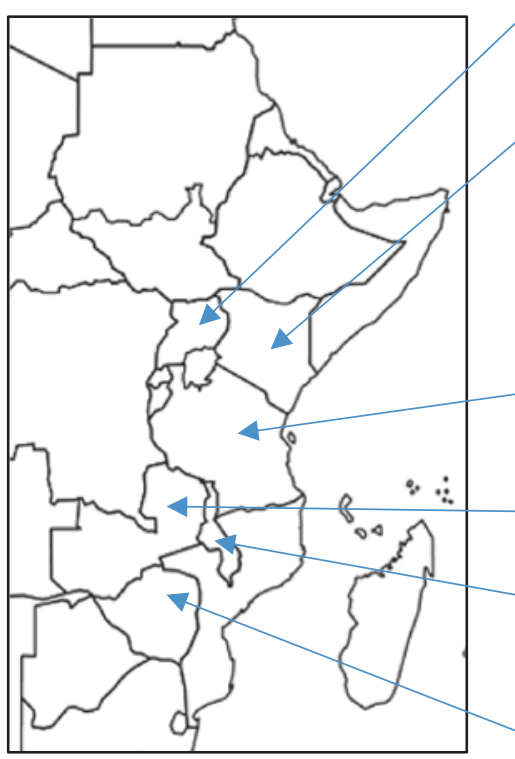

Uganda: Shea (Vitellaria paradoxa)

Kenya: African medlar (Vangueria infausta), balanites (Balanites aegyptiaca), baobab (Adansonia digitata), carissa (Carissa spinarum), guava (Psidium guajava), jujube (Ziziphus jujube), mango (Mangifera indica), marula (Sclerocarya birrea), tamarind (Tamarindus indica)

Tanzania: [Allanblackia stuhlmannii], marula (Sclerocarya birrea), [Strychnos cocculoides]

Zambia: Marula (Sclerocarya birrea), [Strychnos cocculoides], wild loquat (Uapaca kirkiana)

Malawi: Marula (Sclerocarya birrea), wild loquat (Uapaca kirkiana)

Zimbabwe: Wild loquat (Uapaca kirkiana)

Fig. 10.5 ICRAF's and partners' field trials in eastern and southern African nations of perennial NOC that are among the 101 crops considered by the African Orphan Crops Consortium (AOCC 2018). These trials also function as living gene banks. [] indicates a related species to an AOCC crop 
These trials also function as living gene banks that maintain resources for future genetic improvement and climate adaptation. Because some of these trials duplicate species and germplasm sources across locations, they can provide information on responses to environmental variation that is crucial for devising climate adaptation strategies. However, further field experiments are required to properly understand variation in AOCC species.

As well as the need for greater funding for perennial NOC improvement programmes, another key issue is the need to develop delivery systems that can provide smallholder farmers in SSA with improved perennial NOC genotypes. Delivery to smallholders of improved annual crops is also weak in the subcontinent and similarly requires improvement (see other papers presented in this book), but there are specific additional issues faced by perennial trees that require adjusted approaches to annual crops. These include: the wide variety of tree species involved; the range of different possible germplasm sources available; the form in which material is planted by farmers (generally not as seed but as seedlings); the time that trees take to mature; the large amount of offspring that can be produced by any one tree; and the generally low planting densities that are applied during cultivation, due to the large size of mature individuals (Lillesø et al. 2017).

Developing improved germplasm and supporting the participation of small-scale commercial providers, operating at local levels accessible to farmers, have been identified as key for improving current tree crop delivery systems (Lilles $\varnothing$ et al. 2011). Attention to climate-change trends and how these affect planting is also crucial, especially as the longevity of trees mean that measurable changes in climate at specific sites are possible within the life cycle of single generations (Alfaro et al. 2014). Climate planning requires that existing local providers are linked to suppliers that operate over greater geographic distances, such as national tree seed centres. The latter must coordinate the long-distance transfers, often working across countries, which are required to cope with the scale of climate-change trends. These tree seed centres must then also interact effectively with local-level networks that have lower transaction costs to reach farmers efficiently with climate-adapted tree planting material.

An effective delivery system for perennial crops requires a reorientation of the current roles of different actors in germplasm supply (Lilles $\varnothing$ et al. 2011, 2017). For example, non-governmental organizations need to move away from using donor support to supply tree planting material 'for free' to farmers-which inadvertently out-competes local commercial suppliers and is an unstable short-term approach, because of the vagaries of donor funding - to providing business and technical training to support local supplier enterprises. Such reorientation is supported in SSA by ICRAF and partners through training and decision-support tools (Kindt et al. 2006). In addition, modelling 'seed zones' in current and future climates (Kindt et al. 2016) helps to direct the larger scale translocations that are required for adaptation, as illustrated by the case of the perennial NOC marula in East Africa in Fig. 10.6. In this case, particular geographic sources of germplasm are likely to be better adapted under future climates, meaning that these should be the focus of current collection and multiplication (compare Fig. 10.6a, b). 
A) Current

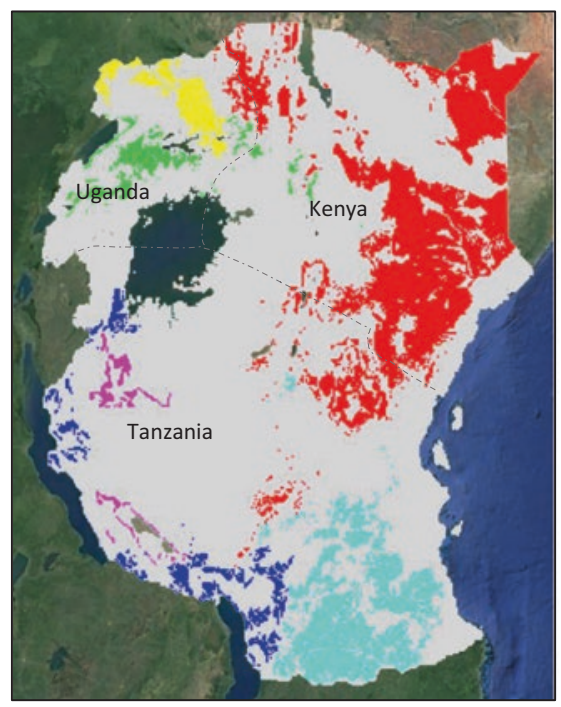

B) 2055 RCP 4.5

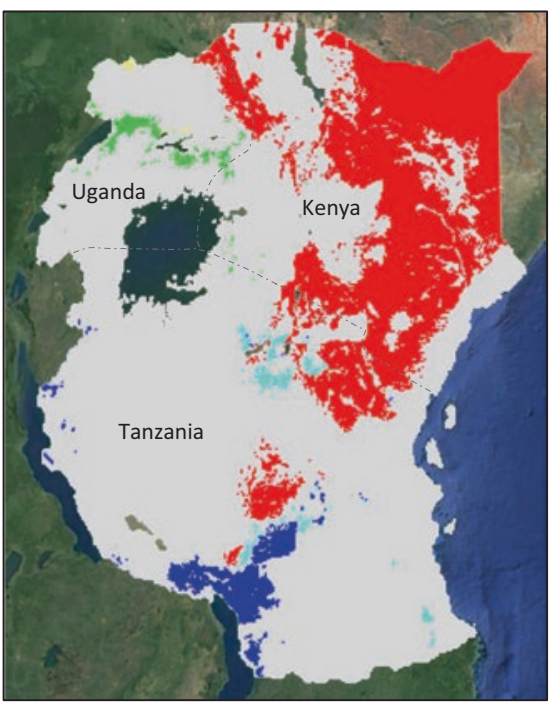

Fig. 10.6 Modelling 'seed zones' in (a) current and (b) potential future climates for marula (Sclerocarya birrea) in East Africa. Details on mapping, which was based on potential natural vegetation and bioclimatic distances from germplasm sources, are given by Kindt et al. (2016). Future climatic conditions centre on 2055 (2041-2070) and represent the mean of ten general circulation models for the Representative Concentration Pathway of $4.5 \mathrm{Wm}^{-2}$. The figure shows the conditions associated with current seed zones on a future climate map and predicts that in the future germplasm from current yellow and light blue zones will be of limited utility in the region, while the area adapted to germplasm from the current red zone will in future expand

\subsection{Implications for Development}

As African nations' economies transform, as people move from the countryside to the cities, and as new production, processing and communication technologies develop, there are new opportunities to integrate perennial NOC into food systems. These arise through new ways of processing and producing food and for informing consumer choices, as well as through the greater incomes of at least some consumers (Dawson et al. 2018b). This integration of perennial NOC aligns closely with the United Nations Sustainable Development Goals to reduce poverty, promote the accessibility and use of nutritious foods, and contribute to the food security of growing cities.

In this paper, we have indicated for eastern and southern Africa how greater use of perennial NOC foods could help support food system resilience at subnational and national levels. We have also given examples of production-based interventions to promote the integration of these crops into food systems that take account of climate change. As well as supporting production improvements by better selection and breeding through initiatives such as the AOCC, a focus on delivering planting 
material to farmers is essential. New approaches to more effectively reach farmers with planting material are required, such as a greater emphasis on business and technical training of local suppliers, including small-scale tree nurseries.

Of course, farmers simply producing more NOC will not in itself lead to the enhanced nutrition of consumers in SSA, as there are many additional interconnecting factors that determine individuals' diets, including culture, economics, policies and agro-environments. This means that a systems-oriented approach is crucial in future research, in which the many additional current barriers limiting NOC integration are properly considered, including market constraints and consumers' behaviour. The creation of interdisciplinary research and development teams to address multiple system-level constraints, across geographic scales, and targeted to different future challenges of which climate change is only one, is thus a priority.

\section{References}

AOCC (2018) African Orphan Crops Consortium. https://www.africanorphancrops.org/. Accessed 12 Jan 2018

Alfaro RI, Fady B, Vendramin GG et al (2014) The role of forest genetic resources in responding to biotic and abiotic factors in the context of anthropogenic climate change. For Ecol Manag 333:76-87

Altieri MA, Nicholls CI, Henao A et al (2015) Agroecology and the design of climate changeresilient farming systems. Agron Sustain Dev 35:869-890

Covic N, Hendricks S (2016) Introduction. In: Covic N, Hendriks S (eds) Achieving a nutrition revolution for Africa: the road to healthier diets and optimal nutrition. ReSAKSS Annual Trends and Outlook Report 2015. International Food Policy Research Institute, Washington, DC

Dawson IK, Vinceti B, Weber JC et al (2011) Climate change and tree genetic resource management: maintaining and enhancing the productivity and value of smallholder tropical agroforestry landscapes. A review. Agrofor Syst 81:67-78

Dawson IK, Attwood SJ, Park SE et al (2018a) Contributions of biodiversity to the sustainable intensification of food production. Thematic study to support the State of the World's Biodiversity for Food and Agriculture. Food and Agriculture Organization of the United Nations, Rome in press

Dawson IK, Hendre P, Powell W et al (2018b) Supporting human nutrition in Africa through the integration of new and orphan crops into food systems: placing the work of the African Orphan Crops Consortium in context. ICRAF Working Paper. International Centre for Research in Agroforestry, Nairobi

FAOSTAT (2017) Food and Agriculture Organization Corporate Statistical Database. www.fao. org/faostat/. Accessed 20 Nov 2017

Garibaldi LA, Aizen MA, Klein AM et al (2011) Global growth and stability of agricultural yield decrease with pollinator dependence. Proc Natl Acad Sci U S A 108:5909-5914

von Grebmer K, Saltzman A, Birol E et al (2014) 2014 Global hunger index: the challenge of hidden hunger. Deutsche Welthungerhilfe, Bonn with the International Food Policy Research Institute, Washington, DC

Hickey JM, Chiurugwi T, Mackay I et al (2017) Genomic prediction unifies animal and plant breeding programs to form platforms for biological discovery. Nat Genet 49:297-1303

Khoury CK, Bjorkman AD, Dempewolf H et al (2014) Increasing homogeneity in global food supplies and the implications for food security. Proc Natl Acad Sci U S A 111:4001-4006 
Kindt R, Lillesø J-PB, Mbora A et al (2006) Tree seeds for farmers: a toolkit and reference source. International Centre for Research in Agroforestry, Nairobi

Kindt R, van Breugel P, Lillesø J-PB et al (2016) Future tree seed zonation in East Africa determined by potential natural vegetation and bioclimatic distance. International Centre for Research in Agroforestry, Nairobi

Lilles $\varnothing$ J-PB, Graudal L, Moestrup S et al (2011) Innovation in input supply systems in smallholder agroforestry: seed sources, supply chains and support systems. Agrofor Syst 83:347-359

Lilles $\varnothing$ J-PB, Harwood C, Derero A et al (2017) Why institutional environments for agroforestry seed systems matters. Dev Policy Rev 2017:1-24. https://doi.org/10.1111/dpr.12233

McMullin S, Njogu K, Wekesa B et al (2017) Developing fruit tree portfolios for filling food and nutrition gaps: guidelines and data collection tools. International Centre for Research in Agroforestry, Nairobi

Powell B, Thilsted SH, Ickowitz A et al (2015) Improving diets with wild and cultivated biodiversity from across the landscape. Food Secur 7:535-554

Ray DK, Ramankutty N, Mueller ND et al (2012) Recent patterns of crop yield growth and stagnation. Nat Commun 3:1293

Sibhatu KT, Krishna VV, Qaim M (2015) Production diversity and dietary diversity in smallholder farm households. Proc Nat Acad Sci USA 112:10657-10662

Thibaut LM, Connolly SR (2013) Understanding diversity-stability relationships: towards a unified model of portfolio effects. Ecol Lett 16:140-150

WACCI (2018) West African Centre for Crop Improvement. https://www.wacci.edu.gh/. Accessed 12 Jan 2018

Open Access This chapter is licensed under the terms of the Creative Commons Attribution 4.0 International License (http://creativecommons.org/licenses/by/4.0/), which permits use, sharing, adaptation, distribution and reproduction in any medium or format, as long as you give appropriate credit to the original author(s) and the source, provide a link to the Creative Commons license and indicate if changes were made.

The images or other third party material in this chapter are included in the chapter's Creative Commons license, unless indicated otherwise in a credit line to the material. If material is not included in the chapter's Creative Commons license and your intended use is not permitted by statutory regulation or exceeds the permitted use, you will need to obtain permission directly from the copyright holder.

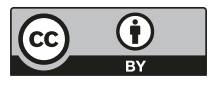

